the contents of the duodenum, because of some fault in the technic. Now its contents are washed out with the stomachtube. These patients in the beginning died because we didn't know how to use the stomach-tube. There was no place for the duodenal contents to flow. They couldn't pass up into the stomach and couldn't come through the anastomosis because it was kinked, and these patients died within from three to five days. When I heard Dr. Draper's paper I couldn't understand some of the mortality after operations of that kind, either of my own or others. Patients going well on the operating-table, apparently absolutely comfortable for twenty-four or thirty-six hours, suddenly going to pieces, with no pumping, no distension or rapid pulsing that show in intestinal obstruction. That is a definite case of death from acute dilatation of the duodenum as a definite postoperative complication. If there is a patent pylorus we can relieve that with a stomach-pump when the pylorus is closed by section. Some surgeons are now advocating that posterior gastro-enterostomy is without an element of danger, and will not be followed by complications in two or three days. The operation has led to chronic dilatation of the duodenum, a terminal condition which is responsible for the ill-health of a group of patients. In the last three years I have recognized and operated on six. In the previous three years I didn't recognize three. The previous three died. The subsequent six have recovered, and the cause of the dilatation I have found has been a congenital defect in the mesentery to the ileum from the appendix and the giant cecum descending into the pelvis, and on account of the short mesentery of the ileum lying directly on the base of the mesentery section, which kinks the small intestine as it passes through to a junction with the duodenum, which produces a chronic dilatation with its symptoms. These patients have been relieved by removing the colon and taking away that heavy part and exposing the transverse colon so that it will do its work and be allowed to expand. This is a demonstration of what experimental physiology can do for practical surgery.

\section{ROVSING'S OPERATION FOR CONGENITAL CYSTIC KIDNEY*}

F. B. LUND, M.D. BOSTON

My first acquaintance with congenital cystic kidney was gained in the dissecting-room of the Boston City Hospital, where I saw several necropsies on patients of middle and adult life who had come into the hospital in convulsions and died of uremia. In some of them, the enlargement of the kidneys had been noticed before death; in others, not, but at the necropsy the kidneys were found very much enlarged and studded with numerous cysts ranging in size from a pea to an orange. These cysts were yellow, green, red and brown, and the effect was very beautiful, making a pathologic specimen truly remarkable and imposing in appearance. These necropsy cases were bilateral, one kidney being considerably more enlarged than the other.

Cases in which gradual enlargement of a polycystic character takes place in middle life, and in which the patients present themselves to the surgeon on account of dragging pain and the presence of a tumor in the loin, or possibly on account of the mobility of the enlarged kidney, may suggest malignant disease of the kidney or hydronephrosis; and it is frequently only when they are cut down on that their true nature is revealed and the importance of a knowledge of their

* Read before the Section on Surgery, General and Abdominal, at the Sixty-Fifth Annual Session of the American Medical Association, Atlantic City, N. J., June, 1914. nature and treatment becomes evident. Such kidneys have not infrequently been removed, with the result that the patients have died of uremia, and the necropsy has revealed the presence of cystic disease of the other kidney, usually less advanced, so that a tumor was not felt before operation. A knowledge of the fact that this disease is usually bilateral might have saved the patient's life and the surgeon's discomfiture.

Congenital cystic kidney is a disease which frequently runs its course without a diagnosis being made during life, death occurring from uremia or cerebral hemorrhage due to kidney insufficiency. The real cause of the insufficiency is first discovered at the necropsy, when the enlarged cystic kidneys, not felt during life, are found by the pathologist. In fact, the course of the disease may be so latent that a patient in whom pathologic changes have not been suspected may be stricken with uremia or cerebral hemorrhage.

The term "congenital cystic kidney" does not include hydronephrosis, which is a dilatation primarily of the pelvis and sinus of the kidney from retention due to obstruction in the pelvis itself or the ureter, and does not concern the urinary tubules at all. It does not include cystic dilatation of the tubules due to contraction of the interstitial tissue, which sometimes accompanies a chronic interstitial nephritis. Here the kidney cortex becomes studded with little cysts, seldom larger than a pea, and not, as in the true congenital cystic kidney, greatly enlarged and varying in size. The cysts in interstitial nephritis play only a subordinate rôle and are secondary to scar contraction. Neither does the subject under discussion include the single or occasionally multiple cortical cysts which sometimes result from the absorption of embolic infarcts. In the true cystic kidney the organ may be enormously enlarged; for example, the cases in which they present an obstacle to parturition or in adults occupy half or two-thirds of the abdominal cavity. The whole organ, both cortex and medulla, is studded with cysts of various sizes, from that of a pin-head to that of a mandarin orange. The surface is knobby with cysts of different size and color. The walls of the cysts are thin and vascular, and the larger ones show folds on their inner surface, which are the remains- of the walls of the smaller cysts which have coalesced to form them. The fluid consists of urine, since in it are found urinary constituents, such as uric acid and hippuric acid, calcic oxilate, cystin, leucin, and tyrosin; but in the larger cysts, this fluid is considerably diluted (probably by serum which has transuded through the walls), is albuminous, and contains blood, pigment, fat and cholesterin, in varying quantities, so that the color of the cysts may be red, brown or yellow, and the fluid in them more or less cloudy. Between the cysts are often found more or less extensive areas of normal renal parenchyma; other cysts are separated merely by fibrous tissue. In some cases with large amounts of parenchyma, we cannot distinguish between cortex and medulla.

The efferent passages which protrude into the calices or pelvis frequently show no changes, but in some specimens are shrunken and narrowed, and may be almost obliterated. Thin-walled cysts may sometimes be seen projecting into the pelvis, just as they do on the outer surface of the kidney. Microscopically, each cyst is lined with a single layer of flat epithelial cells, which in the smaller cysts correspond closely to a tunica propria. In the larger cysts this is not found, either because they have no proper wall, or because 
the cysts appear as dilatations in the interstitial tissue. The partitions between the cysts are so thin as to make it probable that the larger cysts have been formed by the coalescence of smaller ones. In some of the smaller cysts, glomeruli have been found attached to the walls, and flattened, but still permeable to injected fluid. It is thus evident that all portions of the tubular tract, from the glomeruli to the terminations in the papillae, are subject to cystic dilatation. The suggestion of certain investigators that these dilatations may arise by cystic degeneration of the interstitial tissue is not supported by recorded observations. That certain of the cysts show no epithelial lining is due to the fact that the epithelium is desquamated and disappears. In the smaller or younger cysts the epithelium is always found.

Cystic kidneys in adults and in the new-born are usually bilateral. If, as is rarely the case, the disease is unilateral, the other kidney is hypertrophied. The degeneration of the kidney may have an unfavorable influence on the development of the fetus, so that birth is premature. The child may die within a few moments of birth from respiratory failure, because of the interference with the movements of the diaphragm consequent on the tumor, or may live a few days, only to succumb to the same cause. Death may result early in these cases from renal insufficiency, the amount of normal functionating renal tissue between the cysts being insufficient for excretory purposes. On the other hand, the amount of normal renal tissue may be sufficient to prolong life for indefinite periods, perhaps decades, before renal insufficiency results in death. The most favorable conditions will naturally be presented by unilateral cases with compensatory hypertrophy of the opposite kidney, which unfortunately are rare.

In considering the etiology or this disease, we enter a field which has been fruitful of much discussion. The theory of Neuwerck, Hufschmidt and von Kahlden, that these tumors are cyst-adenomas, is negatived, it seems to me, by the fact that the cysts may often be demonstrated to be dilatations of the renal tubules, and contain urine, often diluted with serum, it is true, but showing distinct urinary constituents. The epithelial proliferations and connective-tissue growths, which Brigidi and Severi had relied on as evidence of tumor-growth or adenoma, have been shown by von Mutach to be tissues characteristic of embryonic kidneys. The presence of these proliferations, etc., therefore, is an argument in favor of the developmental rather than the neoplastic origin of the tumors. In order to explain these cases we have to assume, with Orth and others, the existence of some obstruction to the escape of urine from the dilated and cystic canals. The oldest theory, that of Virchow, that the urinary concretions, "uric acid infarcts," so common in the new-born, have plugged the canals, is untenable, since these are rare during intra-uterine life, and after birth so common that cystic kidneys, if due to them, ought to be much more frequent than they are. There seems to be no doubt, as Virchow himself acknowledged later, that we must assume an organic obstruction and actual obliteration of the tubules. Orth agrees with Virchow's later view, that the condition results from a fetal inflammation involving the papillae without resulting in obliteration. He says that the papillary atresia cannot be attributed to a congenital narrowing, because certain embryologic investigations have shown that the tubules are devel- oped from the wolffian ducts and do not develop separately from them and afterward unite with them. The fact that we find cysts in all parts of the kidney, including the papillae, does not, however, make it necessary to assume that the obstruction must be located in the papillae. The cysts of the upper tubules might extend into the papillary tract and displace the straight tubules and project into the pelvis.

In favor of the theory that the condition is a developmental malformation is the fact that other congenital malformations frequently coexist. The presence of congenital cystic liver in association with cystic kiuney, which occurs in 19 per cent. of the cases (Moscowitz), is also significant of the embryonal origin of the condition. The cysts of the liver are ascribed by Moscowitz as due to the obstruction of afferent intraacinar bile-ducts, and are evidence also of congenital origin. Other anomalies which have been found associated with cystic kidney are hypospadias, atresia, and absence of ureter, vagina, bladder, etc.; also harelip, spina bifida, or absence of extremities. There is now pretty general agreement among investigators that the condition is due to defect in development, which is explained somewhat as follows: The tubular structure of the kidney, including the glomeruli, the convoluted tubules, the loops of Henle and the straight tubules, to a considerable extent, originate by a development of tubules in the mesoderm of the embryo. The ureter, kidney, pelvis and an uncertain. amount of the straight tubules in the pyramids develop from a tubular process which originates from the wolffian duct. The straight tubules grow out and meet the primitive vesicle, which becomes the glomerulus; and then later from this glomerulus the convoluted tubules and Henle's loops are developed (Brödel). In case this tubule growing from the wolffian duct fails to connect with the primitive glomerular vesicle, an obstruction occurs, resulting in cystic dilatation of the entire tubular system above the straight tubules. The extent of the process will depend on the reiative number of tubules that fail to meet. If a large proportion fail to connect, then the cystic formation will be rapid and complete, and, no kidney tissue being left to eliminate urine, the patient will die. If, on the other hand, there be left comparatively large areas of healthy kidney tissue, enough for the elimination of uric acid, the patient may live for years and die from other causes. The presence of the increasing cystic tissue may finally so squeeze the intervening healthy tissue as to cause insufficiency, and the patient dies from this. This theory seems adequate to explain the facts as observed, and to be in every way more probable than that fetal nephritis involves the papillae. This view has lately been adopted by Berner. ${ }^{1}$

Bunting, in a careful microscopic study of specimens from two cases, found that in these cases the urinary path could be opened from the glomeruli through to the pelvis of the kidney, and, therefore, added no evidence in support of the obstruction theory or a failure of two sets of tubules to join with each other. He believes that the primary cause of the trouble is the epithelial hyperplasia, which, so to speak, forces out the walls of the tubules. This theory does not satisfactorily explain, however, why we get cystic forms instead of epithelial growths, and needs further confirmation. Whatever theory of cystic kidney be adopted, we cannot help concluding that it is

1. Berner, O.: Zur Zystennierenfrage, Virchows Arch. f. path. Anat, 1913, colxv, 265. 
a developmental condition, a malformation rather than a new growth. A fact that speaks strongly for the malformation origin is its occasional occurrence in several generations of the same family, showing a tendency to inheritance.

Cystic kidney has oftenest been observed in the middle decades of life, but cases have been reported in the first and second decades as well. In the adult, the pathology corresponds in every way with that of the new-born except that the individual cysts are larger, as are also the entire kidneys. It becomes evident, therefore, that if our explanation is correct, we must assume that in case of cystic kidney in the adult, the condition has existed since birth but has not until later years given rise to symptoms that attract attention.

If our views of the etiology and pathology of the disease as given above are correct, they will furnish us an adequate explanation of the somewhat remarkable symptomatology and course of the disease. The most thorough and careful description of the course and symptoms which I have found is that of Milward of Birmingham, who divides the clinical history of the disease into three stages:

1. The stage of progressive enlargement of one or both kidneys without subjective symptoms. The renal enlargement is discovered, if at all, by accident. This stage may last from a few months to several years.

2. The stage of subjective symptoms and objective signs. This stage lasts from a few months to six or eight years, or even longer. The sig ${ }_{1} \mathrm{~s}$ and symptoms are dependent on the size and weight of the tumors.

3 . The stage of decreasing elimination of urine. In this stage appear the symptoms of uremia or cerebral complications. It lasts two or three weeks or a few months.

Males and females are affected in about equal numbers. The disease usually terminates fatally in the fourth, fifth, or sixth decade. Renal enlargement is rarely discovered before adolescence, and when the disease develops in infancy, the child hardly ever lives till the tenth year, so that the disease has been rarely reported between the tenth and thirtieth years.

The symptoms noted during the second stage are a dull, aching pain in the region of the kidneys, during both night and day, but usually worse in the daytime, especially if the kidney is movable. A large part of the pain, especially in the later stages, seems to be due to mobility of the kidney. There is tenderness on palpation or pressure, and occasionally the pain may be paroxysmal and very severe, with resulting prostration. Since many of the kidneys removed at operation or examined post mortem present cysts filled with blood under high pressure, it is reasonable to suppose that some of the pain may be due to hemorrhage into the cysts. Occasionally, suppuration has taken place in one or more of the cysts and has required operation. Flatulence, headache, dyspepsia, voniting, anorexia and constipation are frequently concomitant symptoms. It is an important and somewhat interesting fact that the examination of the urine often throws very little light on the diagnosis, a circumstance which contributes greatly to the difficulty of the latter.

During the second stage and until the deformation is far advanced, the kidneys are capable of continuing their functions almost perfectly. The specific gravity is usually low, below 1.010, and the amount passed is usually slightly increased, but may be diminished. There is usually only a slight trace of albumin, and often albumin is entirely absent. In the second stage, it is never present in large quantities except when there is a great deal of blood. Casts are practically always present; leukocytes are common and often occur in large numbers. Pus may be present in acid urine. Blood is usually present in traces, and when there is hemorrhage into the cysts, may be poured out in such large quantities as to constitute attacks of hematuria. Bleeding may occur every few months, or once a year, or may never be sufficient to tinge the urine. Some blood, however, is always present, and this is significant (Milward).

The elimination of urea may amount to from 250 to 350 grains until late in the second stage; and it is not unusual when death occurs suddenly (as it often does in the third stage) for the physician to find to his surprise the cystic kidneys.

The symptoms of the third stage are those of uremia or some allied complication, such as cerebral hemorrhage, due to arteriosclerosis, and consist of headache, dyspnea, drovisiness, convulsions, paralysis and coma.

In the majority of cases the symptoms last from a few months to five or six years. Twenty-two and nineteen years, respectively, was the duration of symptoms in the longest cases noted. Ritchie, reporting on eighty-eight cases, found that in seventy-five, the average age at death was 45.3.

Of seventy-eight cases in which the symptoms were analyzed, thirty had renal symptoms apart from albuminuria, twenty having pains in the loins and abdomen. Sixteen had hematuria at some time. Seven had no kidney trouble, and no evidence of illness, but cystic kidneys were found post mortem. Eleven suffered, or had suffered, from edema; in ten the absence of edema was stated. In thirty-three the urine contained albumin, in nineteen a trace, and in eleven a considerable quantity. Vomiting or intestinal symptoms, constipation or diarrhea, was present in nineteen cases. Twenty showed anemia, cachexia or loss of flesh. Thirteen had dyspnea or some pulmonary affection. In twenty-one, tumor was discovered during life in one or both fianks.

A brief review of the literature shows us that those patients who have come under the surgeon's care presented themseives during the second stage for pain in the side, due either to the weight or to the mobility of the tumor. The surgeon finding the tumor operated, and, if it was large and malignant-looking, not infrequently removed it. The patient lived or died according to the presence or absence in the other kidney of sufficisnt healthy tissue to attend to the elimination of urea.

Several years ago, in cutting down in a case ${ }^{2}$ of movable kidney, I found that I had a case of congenital cystic kidney to treat. I made an incision on the other kidney, and found that also was cystic, so, instead of removing the kidney in this case, I punctured the larger cyst, and sutured the kidney in place, with considerable relief of the symptoms, so that the patient (who was a nurse) was able to go back to work and lived in comparative comfort for many years.

My next experience (Case 4, reported below) was being called to see a woman who was subject to congenital cystic kidney, who had recently had a baby, and following that, had had infection of one of her

2. Lund, F. B.: Congenital Cystic Kidney, The Journal A. M. A., Aug. 18, 1906, p. 479. 
kidneys. This had been incised, and from the wound pus was discharging, and she had had a picket-fence temperature for something like six weeks. I cut down on the kidney, and found a congenital cystic kidney, with many of the cysts infected. Inasmuch as she was rapidly running down from suppuration and there was no way of draining all the separate cysts, I removed the kidney, hoping that the other kidney was not too much involved in the disease. She recovered from the operation and got well. When she became pregnant again, symptoms of swelling of the extremities, dizziness, headache, etc., appeared, and she had to have miscarriage induced twice. Then I removed the tubes, and she has been well and happy sinceabout five years. The other kidney - the right onecan be felt to be considerably enlarged and cystic at the present time, but it is not increasing much in size.

These experiences led me to make a study of congenital cystic kidney, the results of which were published in a paper read before the American Medical Association at its Boston meeting in 1906, from which I have freely quoted.

It is evident from the foregoing discussion that the disease is fatal from compression of the kidney-tissue between the cysts; and that while it may be practically impossible to cure the disease, it might be arrested at any given point if the growth and multiplication of the cysts could be stopped so that the kidney-tissue could be no further compressed between them. This Curtis and Kammerer have attempted to do, and I myself have done it rather inefficiently without knowing of their work, as in the case I referred to at the beginning of this paper. Last year, however, I had the pleasure of a visit from Professor Rovsing, who told me of his results in the treatment of this disease by puncture of the cysts; and under his direction, I was fortunate enough to be able to perform an operation on the right kidney of a patient then in the ward. I have since had the opportunity of the same patient. and on one kidney in each of two other patients, and I am so pleased with the results that I am glad of the opportunity of reporting them.

- Rovsing's operation consists in exposing the kidney through the ordinary oblique incision in the loin, and puncturing the cysts on its surface as far as they can be reached by retracting the wound; and it will be found when you try it, that a very large area of the anterior and posterior surface and posterior border of the kidney can be reached. As the cysts are punctured and the contents flow out, the kidney is much diminished in size, and may be so reduced that one pole and then the other may be delivered from the wound. Then, with the kidney held in the left hand, the larger cysts and bunches of cysts may be felt and the hollow needle run into them. Care should be taken to avoid the areas of normal kidney-tissue wherever they can be seen and felt. There will be very little bleeding unless these areas of tissue are punctured. A kidney which is six, or eight, or even ten times the normal size may by this means be reduced until it is of a very decent size, say perhaps twice the size of a normal kidney. Then the kidney can be replaced in the abdomen, and the wound closed without drainage. It seems like a formidable procedure, but it is not so; and the surprising thing about it is, that the kidney not only is of smaller size when it is replaced in the abdomen, but that after a temporary increase in size, it remains small and no longer troubles the patient by its weight and dragging sensations.
Rovsing ${ }^{3}$ has reported three cases in which this operation was performed. In his first case, reduction in the size of the kidney was permanent, and the albuminuria which was noted before the operation disappeared. The patient lived in comfort for some time, and then died of uremia following fever. In Rovsing's second case, the pain and dragging from an enormous kidney was relieved by this operation, and the patient was well for two and one-half years after the operation. The albuminuria diminished, the urinary excretion tripled, and the urea excretion doubled.

In Rovsing's third case, an enormous kidney was reduced in size, the twenty-four-hour quantity of urine increased, the excretion of urea increased, the patient's appetite improved, and the patient's color became healthy. Rovsing says :

It is to be noted that in these cases, the pain disappeared and renal fuction was reestablished to a striking degree.

There is but one explanation for this unmistakable improvement in the activity of the kidneys. Normal renal tissue is present among the cysts. The pressure of the latter when full and tense inhibits renal function, which is resumed when the mechanical effects of pressure are renoved. The improvement of the patient is also thus accounted for. It is not claimed that the disease is cured by the operation, or that its ultimate fatal issue is more than just postponed. The disappearance of the pain, however, the prolonged and striking restoration of renal activity, the simplicity of procedure and the absence of shock after the operation should constitute a sufficient incentive to attempt this treatment as herein outlined in every case of this type.

My own cases go far to bear out the statements of Rovsing in regard to his operation. I will give them as follows:

CASE 1.-M. M., negress, aged 37, married, who had had eight children and five miscarriages, was admitted to the Boston City Hospital in June, 1910. In May, 1912, lumps were found on both sides, which were diagnosed by her physician as kidney tumor. Appetite was good; bowels constipated; no urinary symptoms. The patient had noticed the lumps for three years. She appeared to be well developed and nourished. Heart, lungs and extremities were negative. There was marked enlargement of both kidneys. Function of left kidney was not good, and operation was advised to relieve pressure.

Cystoscopic examination (Dr. Binney) revealed bladder normal and ureters normal; catheterized for $15 \mathrm{~cm}$.

Functional test: Phenolsulphonephthalein: Color afpeared from right ureter at end of 25 minutes; from left, ?

Right, first hour, 0 ; second hour... 5 per cent.

Left, first hour, 0 ; second hour.... 0 per cent.

Bladder urine ...............

$$
\text { Total ................ } \overline{23} \text { per cent. }
$$

No function of left kidney; very low normal function in right.

June 24, 1912, I made a left lumbar incision. Kidney was exposed and found enlarged to the size of a baby's head, and to consist of cysts. No kidney tissue was found. The cysts were punctured, with discharge of straw-colored fluid until the kidney was small enough to deliver through incision. I continued to puncture the cysts, both deep and superficial, until the kidney was reduced to twice normal size. It was then replaced, and the abdomen sewed up tight. The patient made a good recovery, but tests made about two weeks after the operation showed no apparent change in the kidney function since the operation. The patient was discharged, July 11, after being told to come back in September for an operation on the other kidney.

3. Rovsing, Thorkild: The Treatment of Multilocular Kidney Cys toma (Congenital Cystic Kidney) by Means of Multiple Punctures, Am. Jour. Urol., 1912, viii, 120. 
The urine examination, July 10 , follows:

Pale; cloudy; specific gravity, 1.004 ; acid; slight trace of albumin; no sugar; much pus; few epithelial cells.

The patient returned to the hospital, April 16, 1913. She stated that after leaving the hospital, last July, she felt weak. Complained of pain "across the small of the back" when bending over or when fatigued. Has slept well; good appetite; no nocturia; no trouble in passing water; has cramplike pains in left side of neck, left arm, left shoulder, and in left leg; menses regular; no leukorrhea; constipated. During the previous month, the patient had felt considerably weaker, and complained of headache and langutor.

On physical examination, the patient presented in right upper quadrant an irregular mass extending to middle line and to level of umbilicus, and above to costal border. The mass could easily be seen with patient at ease, moving with respiration. On palpation with one hand on abdomen over mass and other hand in flank, the mass could be moved about freely, with no apparent pain.

April 17, I made a loin incision. The kidney was found much too big to be delivered through the wound. No good kidney-tissue could be seen; nothing but honeycomb cysts of all sizes could be seen or felt in the kidney. I punctured the cysts with a trocar, and much clear and cloudy fiuid (not urine) was withdrawn. After a considerable number of cysts had been punctured and contents evacuated, the kidney was delivered and puncturing of the cysts continued. After reducing the kidney greatly in size, I put it back in position, and closed the wound. Eight days after the operation, the patient was comfortable and passing considerable urine. The mass could be felt, but it was considerably smaller than at entrance, and the patient was discharged May 1.

I saw this patient in the autumn of 1913. She was in good condition, and both kidneys could be felt, but they were not nearly so large as before operation.

Casf 2.-F. S., a woman, aged 35 , married, two children, had had a hard time with the first child, and was miserable for five or six years; suffered from anemia; had pain in right side; seemed as if stomach was floating.

Examination showed a very large mass in the right loin extending down on to the brim of the pelvis. The left kidney could also be felt. The mass in the right loin felt as if cystic. Probable diagnosis was made of congenital cystic kidney, and Dr. Loder examined the urine from both kid neys and reported as follows:

Bladder Urine: Very pale. Specific gravity, 1.005. No albumin. No sugar. Neutral. Urea, 0.2 per cent.

Right Urine: Specific gravity, 1.005. Trace of albumin. Crea, 0.2 per cent. Sediment: Blood and epithelium from catheterization. No pus. No casts or renal cells.

Left Urine: Specific gravity, 1.005. Trace of albumin. Urea, 0.3 per cent. Sediment: Blood and epithelium from catherization. No pus. No casts or renal cells.

Functional Test:

Right: Time, 9 minutes. 84 c.c...22 per cent.

Left: Time 11 minutes. 65 c.c...22 per cent.

Leakage about catheters....... 8 per cent.

Total $\ldots \ldots \ldots \ldots \ldots \ldots \ldots . \overline{52}$ per cent. (1 hour)

Cystoscopy: Trigon shows numerous small, slightly congested areas, slightly elevated. Right ureteral orifice, negative. Left orifice is encroached on on one lip by one of the above-mentioned minute elevations; otherwise normal in size and motion. Catheters passed without difficulty to kidney.

Conclusion: No infection or tumor of kidney. No impairment of function of left kidney.

At the Deaconess Hospital, Aug. 29, 1912, she was placed in a left lateral position for operation on the right kidney. Then the tumor could not be pressed up into position of the kidney, and some doubt was felt as to the diagnosis. An abdominal incision was therefore made at the outer border of the right rectus for exploratory purposes. The left kidney was found to contain numerous large cysts, and the right kidney numerous cysts of various sizes, and a very large cyst at its lower pole. The patient was replaced in the lateral position, and an incision made from the tip of the twelfth rib down and forward to the spine of the ilium. The kidney was dissected out and drawn out of the loin. A very large cyst, which must have contained 4 ounces at the lower pole, was opened and cut away. The other cysts all through the kidney were punctured with a trocar and opened with a knife. There was a good deal of healthy kidney tissue between the cysts. The kidney was reduced to about one-third of its former size, and was sutured to the spinal muscles. In puncturing the cysts, the pelvis of the kidney was opened with a knife, and this opening was closed by suture. A cigaret drain was passed into the loin and the wound sutured to it.

The patient had a high temperature for four or five days, and on September $5 \mathrm{I}$ found pus in the lower angle of the wound. I opened it up, and found a cavity containing about 2 ounces opposite the lower pole of the kidney.

After operation, there was a large increase in the amount of urine passed. The patient made a good recovery, and during the winter and spring of 1912-1913 she gained in flesh, color, and general appearance. Oct. 15, 1912, Dr. Loder made a phenolsulphonephthalein test, as follows:

Right: Time, 9 minutes. 35 c.c....24\% Urea, $0.4 \%$

Left: Time, 9 minutes. 40 c.c......22\% Urea, $0.3 \%$

Leakage ...................10\%

$$
\text { Total } \ldots \ldots \ldots \ldots \ldots \ldots \ldots, \overline{56 \%}
$$

This test as compared with that before the operation shows a doubling of the amount of urea in the excretion of the right kidney.

I saw this patient in June, 1914-that is, nearly two years after the operation-and she is in excellent health. She has good color, and looks much better than when she was operated on. The right kidney (the one operated on) could just barely be felt. The left kidney could also be felt and is a little enlarged.

The urine examination, June 15, 1914, was:

Slightly cloudy; acid. Specific gravity, 1.010. No sugar. Slightest possible trace of albumin. Sediment: Few small round renal cells. No pus, blood or casts.

CASE 3.-C. S., woman, aged 41. One child, instrumental delivery twenty years ago. For about a year, had been growing thin and weak; complexion had become sallow; and she had suffered considerable abdominal pain, especially in the flanks. She had consulted her physician, Dr. C. H. Miller, merely for debility. He had discovered tumors in both flanks, and sent her to me.

On examination, I found her thin and pale. There was very marked enlargement of both kidneys, especially of the left.

Urinary examination by Dr. I. J. Walker, was as follows: Specimen from bladder: Cloudy. Specific gravity, 1.014. Acid reaction. No sugar. No bile. Slight trace of albumin. Sediment: Some blood; some small and large renal cells; a few bladder-cells; a few leukocytes; no casts.

Cystoscopic examination was as follows: Bladder walls normal in appearance. Right and left ureteral orifices normal in appearance. Ureters catheterized and specimen obtained from each kidney. Flow from right kidney about five times greater in amount than that from left kidney.

Specimens showed the following:

Right: Pale. Slight trace of albumin. Sediment: Many small round renal cells, and a few large round renal cells. Rare normal blood corpuscle. Few hyaline casts in about twenty fields.

Left: Much normal blood. Many small round renal cells, and a few large round renal cells. A few leukocytes. One hyaline cast found.

Functional test: Color appeared from right kidney in twelve minutes; from left, in seventeen minutes. Urine collected in one hour showed: right kidney, 20 per cent.; left kidney, 2 per cent.

Rovsing's operation was done at the Boothby Hospital, March 29, 1913: Oblique left lumbar incision. Enormous polycystic kidney found. A very thorough puncture of the kidney was done with a moderate-sized 
aspirating needle, running it thoroughly all through the kidney wherever a cyst could be found. The cysts on the surface appeared to extend out into the surrounding connective tissue. By puncturing the cysts, marked diminution in the size of the kidney was made, and it was finally drawn outside the abdomen. When I finished, the kidney was about twice normal size, and about one-fourth the size it was when we started to operate. In puncturing the cyst in the upper pole, a moderate amount of blood was obtained. Having punctured all the cysts we conveniently could, the kidney was replaced and sutured with chromic catgut sutures. A cigaret drain was placed in the lower angle of the wound. The patient bore the operation well.

Before the operation, the patient was passing from 30 to 45 ounces of urine; the following is the report of the urine examination made two days after the operation: Cloudy. Acid reaction. Specific gravity, 1.008. No sugar. No bile. Slight trace of albumin. Seciment: Some normal bloor (about 60 corpuscles to a field), a few small round renal cells; occasional large round renal•cells; a few bladder cells; rare ureteral cells; much amorphous urates.

The amount of the urine increased; the kidney increased somewhat in size and afterward diminished, and has since remained so it can hardly be felt to have increased in size. The patient has made a considerable gain in flesh, strength, and general appearance. No urethral catheterization has been done since the operation.

I saw this patient in June, 1914, a year and three months after the operation. The left kidney (the one operated on) could just barely be felt. The right is certainly as large as the left was before operation. Her face has filled out, and she feels much better. She is going to come in the autumn to have the other kidney operated on.

Examination of the urine, June 15, 1914: Slightly cloudy. Acid. Specific gravity, 1.006 . No sugar. Slight trace of albumin. Sediment: Many bladder-cells. Considerable number of leukocytes. Few small round renal cells. No blood or casts.

CASE 4.-C. J., a young married woman, seen in consultation with Dr. Bateman at the Somerville Hospital, in 1907. Her father had died at the age of 50 with cystic kidneys. She had been trained as a nurse, and had recently married. Four months before, she had had a baby, which was born in normal fashion. After the baby's birth, the patient had had a high temperature and complained of pain in the right side. Three weeks before, a surgeon had been sent for, who found a tumor in the region of the left kidney, made an incision, and found several cysts, some of which contained pus. After the operation, the patient had a temperature from 100 to 103 , and suffered pain, although she passed a fairly normal amount of urine.

I found a discharging sinus in the left side, and a large tender kidney on that side. The right kidney was also palpably enlarged. June 29, through the sinus, I found a large kidney studded with cysts of various sizes and colors, some of them containing pus. It had been recognized that suppuration from that kidney was the cause of her symptoms, and that it was therefore necessary to remove this kidney. This was done, the pedicle being sewed with catgit. Considerable pus escaped from several cysts. Her pulse was about 140 during operation. July 2, she was reported in good condition.

I saw the patient again, two years after the operation just reported. In the meantime, she had had to have two abortions done by Dr. Bateman, as she had become pregnant and the condition of her kidneys would not allow her to go through pregnancy. She had recently become nervous and suffered a good deal of pain in the left side of the pelvis. Examination showed the uterus movable. The left ovary could be felt to be prolapsed, and this was thought to cause her pain. Median laparotomy was done. The prolapsed left ovary and tube were removed, and the right tube was removed, the right ovary being left behind. This was done to prevent future pregnancy. The right kidney could be felt very much enlarged and cystic. The patient made a good recovery.
As a result of my experience in these four cases, although it is not a large one, I am inclined to think that Rovsing's suggestion of a thorough, systematic puncturing of all the cysts until the kidney is brought down to near normal size is a distinct advantage to our therapeusis in these cases; and I am inclined to feel that $I$ shall perform it in all cases in which the kidney secretion is not too greatly crippled so that any operation might bring on uremia. I believe that in the present state of our knowledge, it is wise, in case both kidneys are involved, to operate on only one kidney at a time. Even if we cannot absolutely cure our patients and make them as good as if they had never been subject to the disease, if we can relieve them of pain and dragging, as I think it has been demonstrated that we can, improve their health, weight, appearance and color, and practically arrest the disease, it seems to me that we can accomplish a good deal. And we must give to Rovsing the credit for having improved and systematized the method of puncture of the cysts-which had been tried in a halfhearted way by others, including myself-until it has a really distinct therapeutic value. ${ }^{4}$

\section{Beacon Street.}

\section{ABSTRACT OF DISCUSSION}

DR. D. N. Eisendrath, Chicago: Dr. Lund's paper is an example of what modern pathology has taught us. Formerly we thought that a congenital cystic kidney was only of interest to the pathologist, but now that we have come to see it under various clinical forms, it becomes of great interest to the surgeon. These cases, formerly regarded as absolutely hopeless, are now amenable to such an operation as Rovsing's for at least temporary relief and the prolongation of the patient's life for a number of years. I differ with Lund only with regard to the priority of this operation. Dr. Witherspoon of Butte, Mont., at our meeting at St. Louis first presented this operation in this country. I think Dr. Witherspoon deserves equal credit with Rovsing for this, having worked independently of him. The clinical picture is cre every general practitioner as well as the surgeon should know. Many cases show first of all marked symptoms of uremia. In a case of uremia think of the possibility of a congenital cystic kidney as a basis and examine the abdomen. In a comparatively early period you will find a kidney which you can recognize as of the congenital cystic variety; the kidney is lower and easily palpated for that reason. It has a lobulated, soft surface. I made the diagnosis in one case three years ago, first in one kidney and then watched

4. In addition to the references already given, the following will be found of interest:

Albarran, J., and Imbert, L.: Les tumeurs du rein, Paris, 1903.

Anglada, Jean: Etude anatomo-pathologique et classification pathogénique d'un cas de reins polykstiques bilateraux, Jour. d'urol. méd. et chir., Feb. 15, 1913, p. 139.

Bovée, J. Wesley: Bilateral Polycystic Degeneration of the Kidneys, South. Med. Jour., March, 1909, p. 576.

Rischbieth, H., and DeCrespigny, C. P. C.: Polycystic Disease of Kidneys: Remarkable Persistence of Functions in Two Cases of Adults, Lancet, London, Feb. 15, 1913, p. 450

Garceau, Edgar: Renal, Ureteral, Perirenal and Adrenal Tumo:s and Actinomycosis and Echinococcus of the Kidney, New York, D. Appleton \& Co., Feb. 15, 1909.

Lipskeroff, A.: Ein Fall von solitärer Zyste der Niere, Folia urol., vi, 1911-1912.

Rovsing, Thorkild: Die Krankheiten der Harnorgane, Lehrbuch der Chirurgie, 1909, ii, part 2, p. 241.

Steiner, P.: Ueber polycystische Nierentumoren, Folia Urol., 1912, vi, 542 .

Vogel, Robert: Beiträge zur Nierenchirurgie; 2 Fälle von Nierencyste, Zentralbl. f. Chir., Nov. 9, 1912, p. 1540.

Rosenow, Georg: Polyzystisches Nierenrudiment bei Fohlen des Ureters und Vas deferens, appendikulärer Schwellkörper des Penis und zahlreiche andere Missbildungen bei einem 8 monatlichen Fötus. Zugleich ein Beitrag zur Entwicklungsgeschichte der menschlichen Niere, Virchows Arch. f. path. Anat, 1911, ccv, 318. Torrance, Gaston: Nephrectomy for Polycystic Condition of the Kidnev. Am. Jour, Obst., April, 1913, p. 736. 
the development of the condition in the opposite kidney. The sarie condition confronted us in that as in one of Dr. Lund's cases, namely, pregnancy. It was necessary to interrupt pregnancy on account of the threatened uremia which would have undoubtedly ensued. The second clinical symptom of this kidney condition is hematuria; a fair proportion of cases of severe bleeding from the kidneys is probably due to such a condition. In every case, congenital cystic kidney appears as a tumor. A large, soft, lobulated tumor of the kidney accompanied with hematuria should be considered among other causes, as due to this condition. It has been supposed to be useless to operate in these cases because they are bilateral, but as Dr. Lund has pointed out, the benefit from such operations is so great that we ought not to abandon them. At a recent meeting of the American Urological Association Dr. Barnett of Fort Wayne reported one case of his own and quoted, among others, four cases of Dr. Ochsner, in which they removed such a kidney, thinking that the condition was unilateral. This condition is always bilateral and if one kidney is ahead of the other in the development of the condition the other will surely catch up with it, and it is perfectly useless to take out one kidney. The condition is due to lack of union of the proximal and distal portions of the urinary tract.

DR. A. L. Chure, Boston: In such experience as I have had the condition has invariably been bilateral. In Walker's new book on this subject he gives some figures concerning the relative frequency of unilateral and bilateral polycystic kidneys. He says that in only one case in thirty is the disease confined to one side. This too small a proportion to allow one to consider nephrectomy in these cases. The last case that I saw illustrates the other point-that of the infection of these kidneys. This patient, a woman of 47 , had a history of some renal trouble six years before. This was supposed to be Bright's disease and she improved considerably under treatment. The latter part of last December she had an attack of pain, first in the right side, then in the left. She had a moderately elevated temperature with these attacks. I easily could feel a mass in her left side. I thought this was due to hematogenous infection and that it would quiet down without any interference. The temperature kept up and I operated on this kidney and found two pockets of pus which I thought were abscesses in the cortex, and which I opened. After the operation, the temperature kept up and the patient became apparently uremic and died four days later. Necropsy showed that there were several other infected cysts in the kidney I had operated on; and that the other kidney was also polycystic and contained likewise a number of suppurating cysts. The question has been raised as to the advisability of removing these kidneys when they have become infected.

Dr. Arthur Dean Bevan, Chicago: I have had six or eight of these cases under observation. The first point I make is that this condition is not always bilateral, or if it is the condition varies so on the two sides that nephrcctomy is not entirely eliminated from consideration. I think it is, in the majority of cases, but I have had two cases in which we made a nephrectomy for polycystic kidney with practically permanent results. The first case was one in which, a number of years ago, a patient came to me complaining of severe hemorrhage from the kidney. The hemorrhage was extreme. The man was very anemic. It was before the days of the phenolsulphonephthalein test and at the time we were using cryoscopy. The cryoscopic examination of the blood, not of the urine, showed a fairly normal condition and with that as a guide I did not hesitate to remove an enormous polycystic kidney on the right side from which ihe blood came. The man made an uneventful recovery and years later I saw him and he was perfectly well. Another case some time later, in a woman, was much the same condition, with recovery, so that, although in the great majority of these cases the condition is bilateral, there is a certain number in which it is unilateral, and a nephrectomy is not entirely excluded. In a number of cases in which I have found extensive polycystic conditions in both kidneys at the time of the exploratory operation, I have been surprised to find, when a purely exploratory operation has been made, that the patients have recovered and have lived for years. The condition slowly progresses and the finding of this polycystic degeneration does not mean anything like an immediate menace to the patient's life. I believe that the work done by Rovsing and Dr. Lund shows a definite and distinct advance. I have not employed this operative procedure, but in the next case of polycystic degeneration of the kidney with which I have to deal I shall certainly employ the Rovsing-Lund procedure. I believe it is perfectly rational and a common-sense proposition and that it does hold out definite benefit to the patient.

Dr. Albert J. Ochsner, Chicago: I wish to bring out two practical points. In this class of cases the patient's condition will be enormously improved by a proper diet. A patient who was a perfectly useless suffering invalid has been able to teach school the entire year with perfect comfort by simply confining herself to the food that one would provide for any patient who has not enough active kidney tissue to do the physiologic work; namely, milk, buttermilk, cooked vegetables, fruits and fruit juices. In the place of meat these patients should eat from two to six eggs each day. By adhering to this diet one will be amazed at the improvement in the condition. Three twenty-minute roentgenizations will produce sterility. Why should the tubes and ovaries be removed in a case in which sterility can be obtained in this safe and simple manner? I have a patient at present under this treatment. This, of course, applies to every female in whom, to prevent uremia, sterility must be secured. In order to make absolutely sure I gave this patient six exposures directly over the ovaries on successive days and feel perfectly certain that pregnancy cannot occur.

Dr. F. W. McRAe, Atlanta, Ga.: I operated in one case of congenital kidney which was certainly unilateral. I came on the kidney accidentally in doing an operation for acute appendicitis on a patient in September, a year ago. The patient was brought in in a rather extreme condition and in making a transverse incision in removing the appendix I found a large cystic tumor. I was not familiar with Dr. Rovsing's work, though I knew of Dr. Lund's. I felt it was safer to make another incision and drain the kidney. The exploration enabled me to examine the opposite kidney and it seemed perfectly normal. The drainage lasted over three months and during that time I had one of our best genito-urinary men make cystoscopic examinations and try to find communication between the kidney and bladder above and below. There seemed to be no connection. In January I removed the kidney. The boy was 14 years old and since that time has increased in weight from about 70 to 110 pounds and is in perfect health. The cyst after draining became infected with a pyocyaneus infection, and the boy's condition became bad, so that it was absolutely necessary to remove the kidney, which the father hesitated to have done. This case proved beyond question that some of these paticnts may be operated on and permanently cured.

Dr. F. B. Lund, Boston: I would not deny the existence of unilateral congenital kidney eyst, but in all necropsies that I have seen they have been bilateral. So large a proportion are bilateral that we should not think of nephrectomy without inspection to ascertain whether the other kidney is normal. Nephrectomy should be done unless there is sufficient kidney function in the diseased kidney to make it worth saving, in which case Rovsing's operation could be done on the diseased kidney, even if the other kidney is healthy. With regard to the use of Roentgen rays for producing sterility, I did not take out the ovaries to produce it; I tied off the tubes and removed one of the ovaries because it was somewhat cystic.

The Source of Dogmatism.-Gross ignorance produces a dogmatic spirit. He who knows nothing thinks that he can teach others what he has himself just been learning.- La Bruyère. 